\title{
Numeric Analysis of the Eigenfrequen- cies of the Ductile Cast Iron with the Spheroidal Shape of Graphite
}

Ján Vavro(SK) vavro@fpt.tnuni.sk

Ján Vavro, jr. (SK) vavroovb@fpt.tnuni.sk

Marián Handrik (SK) marian.handrik@fstroj.uniza.sk

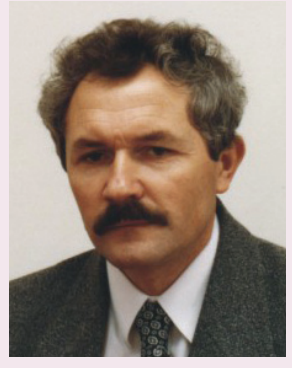

\section{BIOGRAPHICAL NOTES}

prof. Ing. Ján Vavro, PhD. (1952) he accomplished academic education in Faculty of Mechanical Engineering at University in Žilina in 1997. He obtained the academic title CSs. (PhD.) in Faculty of Mechanical Engineering at University of Žilina in 1988. His habilitation and obtaining the title of Assistant professor in scientific field Applied Mechanics in 1995 are also connected with this faculty. In 2005, he was inaugurated in scientific field Applied Mechanics in Faculty of Mechanical Engineering at Technical University in Košice and he was appointed to be professor in 2006. He has been working in Faculty of Materials Technologies in Púchov since 1997 and he became the Dean of this faculty in 2008. His scientific and research work is especially focused on static and dynamic analysis of mechanical systems and their optimization from the aspect of their material properties. He is a member of Scientific board in Faculty of Industrial Technologies, TnUAD as well as at FMMI in VŠB in Ostrava. He is also member of commissions for home and international scientific conferences. He is author or co-author of more than 200 scientific papers and works and he did more than 50 analyses for industry.

Ing. Ján Vavro, PhD. (1982) he accomplished academic education in Faculty of Industrial Technologies with seat in Púchov at Alexander Dubček University in Trenčín and it was exactly in 2006. He finished doctoral study in the study field 5.2.26 Materials, in Faculty of Industrial Technologies with the seat in Púchov in 2009. He has been working as lecturer at Faculty of Industrial Technologies with the seat in Púchov since 2009. His scientific and research work is connected with the whole systems of problems relating to identification of defects in materials. He uses various research methods, such as modal analysis, static and dynamic analysis of mechanical systems of entities and their optimization from the aspect of their materials properties. He is author as well as co-author of more than 36 scientific papers and works and he is also co-investigator of projects, such as VEGA, KEGA and AV.

Ing. Marián Handrik, PhD. (1974) he works as a research worker at University of Žilina in Žilina. He accomplished his academic education in study field Applied Mechanics in Faculty of Transport and Communications (2008). He finished his doctoral study in Department of Applied Mechanics, in Mechnical Faculty at University of Žilina. From the aspect of his scientific and research activities, he is co-author of 48 scientific papers and works. He did more than 35 various analyses for industry relating to linear and non-linear mechanics. He especially pays his attention to whole systems of problems relating to 
FEA which is used for calculation of contact of bearing fits and optimization of constructions.

\section{KEY WORDS}

Eigenfrequencies, Eigenshapes, Modeling of Shape of Nodular iron Nodule, Finite Element Method

\section{ABSTRACT}

The given work is focused on the analysis of the eigenfreqencies and natural shapes as well as it is connected with stress distribution in the frequency area referring to the ductile cast iron with the spheroidal shape of graphite. The analysis was made with help of finite element method (FEM) in the software system ADINA.v.8.6.2.

\section{INTRODUCTION}

The progress of the numeric processes is closely concerned with the new possibilities and new opportunities of materials engineering including modelling of structures of materials and their simulations for various types of loading. The process of deformation is connected with the foreseeability and understanding of microstructure properties because it is really important for knowledge and specification of defect formations of castings during the process of their production or during the moulding processes [1], [2]. In the recent years, the microstructure modelling and its simulation has played quite important role because of finding out of properties and suitability of usage of the given material before its production.

The finite element method allows us to operate with atypical parameters of microstructure. Nowadays, this method is commonly used in the various scientific fields and spheres. In addition, the most common usage can be found in mechanics, materials engineering, thermodynamics and biomechanics etc. [3], [4]. All types of simulations reduce the given specific construction process and there is also opportunity to test or investigate the model at various working conditions and loadings.

\section{STRUCTURE OF CAST IRON WITH THE SPHEROI- DAL SHAPE OF GRAPHITE (SGCI)}

The structure of the basic metallic microstructure of SGCl influences many factors. Two of these many factors are very important because they are connected with the differences of characteristics of austenite transformation which is carried out at unchanged conditions. Influence of chemical composition and influence of cooling speed are the given and important two factors which are mentioned hereinbefore. According to this mentioned fact, there can be the occurrence of ferritic, ferritic-pearlitic or pearlitic structure for cast irons Fig. 1. Pearlite can be the most often found in lamellar form. Increasing pearlitic proportion means increasing of strength, hardness and wear resistance.

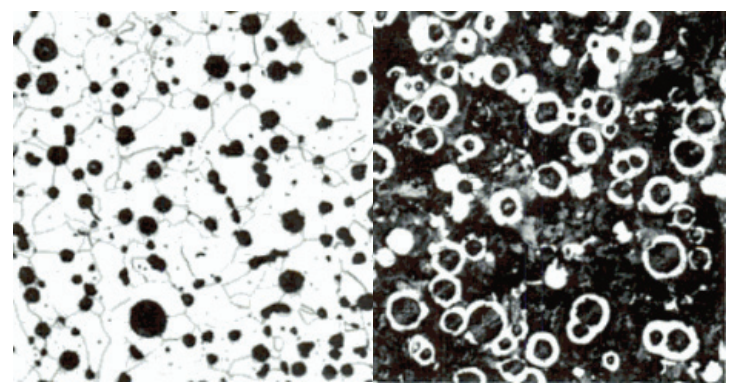

Fig. 1 Microstructure of SGCl, etched by Nital, zoomed $100 x$

On the other side, plasticity and toughness decrease. From the other point of view, the presence of ferrite causes decreasing of strength properties but ductility, toughness and machinability. Moreover, structure as well as properties of SGCl can be influenced by alloying process and thermal treatment in some particular limiting cases. There are some alloying elements which are quite commonly used: $\mathrm{Cu}$ and $\mathrm{Ni}$ - increase plasticity and toughness; Mn and Mo decrease plasticity and increase through-hardening ability. Low content of Mn ensures higher ductility and impact strength. Granular graphite is the other component of the structure Fig. 2. From the aspect of stress concentration, the granular graphite is the most advantageous alternative for separation of graphite [5].

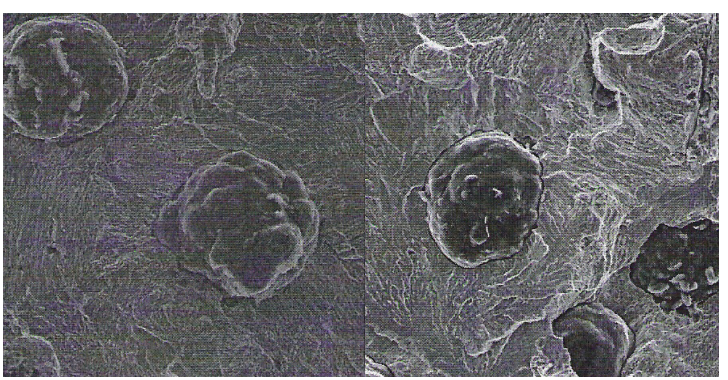

Fig. 2 Images of separated spheroidal graphite in SGCl 


\section{PROPERTIES AND USAGE OF SGCI}

SGCl belongs to iron carbon alloys and there are also other elements. Its structure consists of basic metallic substance - matrix and the graphite can be found in this matrix. This graphite has a specific shape. It is sort of the regular granular grains. From the aspect of the shapes, this shape of graphite has the least notch or impact effect. Doe to this fact, $\mathrm{SGCl}$ has very good mechanical properties and therefore $\mathrm{SGCl}$ can be included among the most common materials which are suitable for manufacturing of castings [6], [7]. If we start to talk about industry of the highly-developed countries, castings of SGCl are used instead of steel castings as well as weldments and forgings and there are the reasons:

\section{- Production costs are lower than 40\%; \\ Specific weight is also lower than specific weight of steel and it is circa by $8 \%$; \\ - On the base of the matrix structure, the tensile strength reaches the values between $300 \div 900 \mathrm{MPa}$ in cast state and it can even be until $1500 \mathrm{MPa}$ after the thermal treatment;}

\section{- Casting properties are also very good.}

The whole number of criteria and standards is utilized for evaluation of quality of SGCl. These criteria and standards influence mechanical as well as physical properties. The properties of SGCl depend on amount, proportion, type and distribution of graphite but composition of the basic matrix (proportion of ferrite and pearlite) is also very important. From the point of view of unalloyed cast irons, the amount and proportion of the graphite in metallic matrix depends on content of carbon, silicon, manganese as well as it depends on cooling rate, i.e. the thickness of the wall of the cast mould and material of which the cast mould is made [8].

\section{EVALUATION OF THE MICROSTRUCTURE BY IM- AGE ANALYSIS}

Image analysis of the microstructure is carried out for the purpose of obtaining of basic data which are needed for formation of the model that is identical with real state of cast iron. The image analyse was used for evaluation of number of graphetic particles, content of graphite and shape of graphite (via shape factor) and the content of ferrite in basic material was evaluated for etched samples. The process of evaluation can be seen in the images 3 and 4 . The microstructure of the etched samples was scanned from microscope by digital camera JVC TK - C920E and the given digital image was transmitted into the computer and it was zoomed 100x Fig. 3. Before the definition and colored amplification of graphetic particles - visual threshold were made Fig. 3, the recorded digital image had been frozen. Then, the image was cleared up in a binary way - it means that the little particles (inclusions) were excluded from the process of evaluation. After the selection of structural parameters (number of particles, content and circularity) had been made, the evaluation was carried out Fig. 4. The same process was carried out at three random selective areas and obtained measured values were used for calculation of the arithmetical average. The results of measurement were exported into the Microsoft Excel file, where they were used for further processing. On the base of the further processing, these specific data were found out: the number of graphetic particles, the content of graphite and shape of graphite (via shape factor). Shape factor $\mathrm{K}$ represents the circularity and if the value equals to number one, it means that it is circle but if the value equals to number zero, it means that it is straight line. According to the mentioned facts, the circularity can be calculated by help of equation:

$$
K=\frac{4 \pi A}{P^{2}}
$$

where $\mathrm{A}$ is an area of the particle and $\mathrm{P}$ is a circumference of particles. The shape factor can acquire values:

- for lamellar graphite: $K<0,27$;

for vermicular graphite: $K=0,27 \div 0,60$;

n for spheroidal graphite: $K>0,65$ [9].

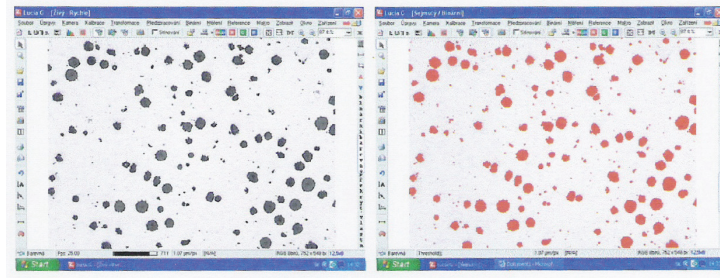

Fig. 3 Downloaded image and definition of particles in the image

The microstructure of basic material can be seen in Fig. 5 and Fig. 6 and it is evaluated on the base of [10]. Metallographic analysis of samples relating to 
basic material Fig. 5 shows that $\mathrm{SGCl}$ is ferritic.

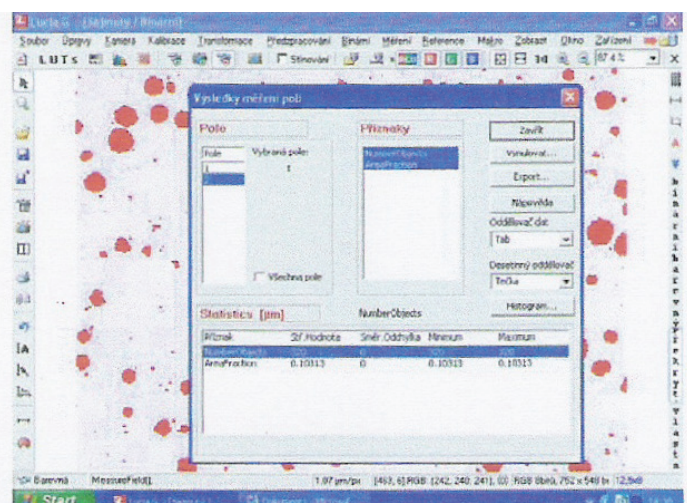

Fig. 4 The evaluation of the given image

The content of ferrite in matrix is in the range from $20 \%$ to $40 \%$. Graphite is separated in the specific shape which is mostly regularly granular (from $60 \%$ to $70 \%$ ) and its minor amount is imperfectly granular (from 20\% to 40\%). The size of regularly granular graphite is form 30 to $60 \mu \mathrm{m}$ and size of imperfectly granular graphite is from 15 to $30 \mu \mathrm{m}$. The microstructure of the material is considerably inhomogenous because there is different size of graphite and number of graphetic particles with respect to unit of the area $\left(\mathrm{mm}^{2}\right)$ and the given mentioned particles were used as semples which were selected from various areas of experimental material as the whole.

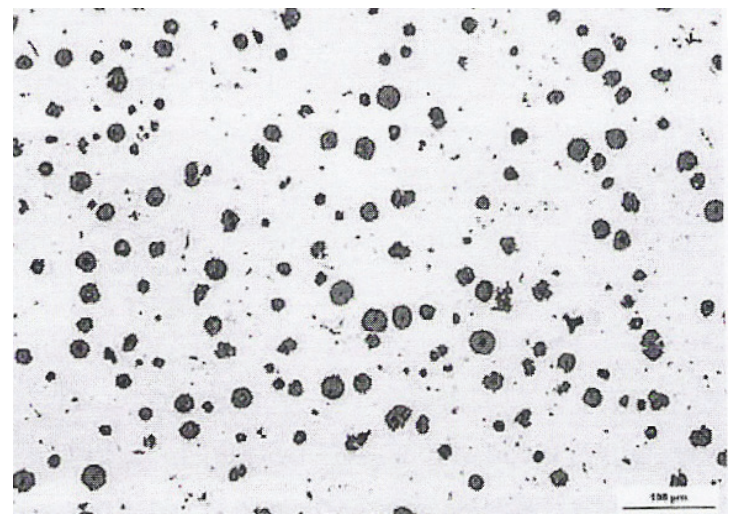

Fig. 5 Microstructure of the sample of basic material referring to $S G C l$, zoomed 100x

The etching action by sodium chromate had been used for specification of different structural parts of ferrite, pearlite, and graphite but it was not possible to specify the segregation of chemical elements. On the base of this fact, etching agent Klemm I was used and by this way, the segregation of the major elements (silicon and manganese), which were dissolved in ferrite could be observed Fig. 6. The content of silicon is the highest around the graphetic particles and on the other side, the lowest content of silicon can be observed at the boundaries of eutectic units - the change of colour from yellow to brown can be seen and in comparison to manganese, there is the contrary development.

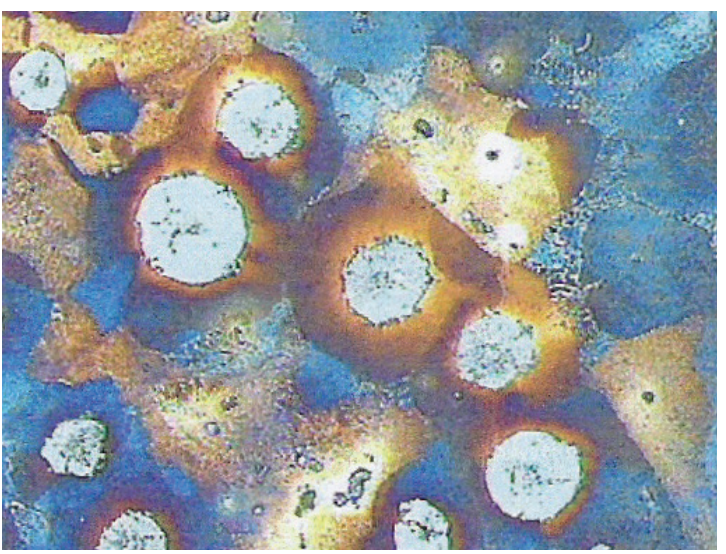

Fig. 6 Chemical segregation of additive elements (zoomed: 250x)

The authomatic image analysis was used as a help for evaluation of etched samples of SGCI where the number of graphetic particles tab. 1, the content of graphite tab. 2 and the shape of graphite - specified with help of shape factor tab. 3. The given etched samples were also used for evaluation of the content of ferrite in $\mathrm{SGCl}$ tab. 4. These obtained results were used as input data for analysis of frequences around the graphetic particles and the given analysis was done with help of model of finite element method (FEM) in the software system ADINA.

The image analysis was used for identification of average number of graphetic particles in SGCl and it was $\bar{n}=212,3$ tab. 1 whereby the area proportion of segregated graphite is $\bar{g}=9,2 \%$ tab. 2 and shape factor is 0,75 tab. 3 . The content of ferrite in the microstructure is approximately $36,4 \%$ tab. 4 and after calculation with help of relation (2), the content of ferrite in matrix is $40,7 \%$.

$$
f_{M}=\frac{f}{100-g} \cdot 100
$$


where

$f_{M}$ - is content of ferrite in matrix

$f-$ is content of ferrite in microstructure

$\mathrm{g}$ - is content of graphite in microstructure

\begin{tabular}{|l|l|l|}
\hline $\begin{array}{l}\text { Sample } \\
\text { designation }\end{array}$ & $\begin{array}{l}\text { Number of } \\
\text { graphetic } \\
\text { particles } \mathbf{n}, \\
\text { [mm } \mathbf{m}^{-2}\end{array}$ & $\begin{array}{l}\text { Average number } \\
\text { of graphetic } \\
\text { particles } \overline{\boldsymbol{n}}\end{array}$ \\
\cline { 1 - 2 } SGCl-1 & 215 & \\
\hline SGCl-2 & 221 & \\
\hline SGCl-3 & 201 & \\
\hline
\end{tabular}

Tab. 1 The evaluation of the number of graphetic particles with help of automatic image analysis

\begin{tabular}{|c|c|c|}
\hline $\begin{array}{l}\text { Sample } \\
\text { designation }\end{array}$ & $\begin{array}{l}\text { Content of } \\
\text { graphite g, } \\
\text { [\%] }\end{array}$ & $\begin{array}{l}\text { Average content } \\
\text { of graphite } \bar{g}\end{array}$ \\
\hline SGCl-1 & 9 & \multirow{3}{*}{9,2} \\
\hline SGCl-2 & 9,8 & \\
\hline SGCl-3 & 8,9 & \\
\hline
\end{tabular}

Tab. 2 The evaluation of content of graphite with help of automatic image analysis

\begin{tabular}{|l|l|c|}
\hline $\begin{array}{l}\text { Sample } \\
\text { designation }\end{array}$ & \multicolumn{1}{|l|}{$\begin{array}{l}\text { Shape factor } \\
\text { (circularity) K }\end{array}$} & \multicolumn{1}{l}{$\begin{array}{l}\text { Average } \\
\text { diameter } \overline{\boldsymbol{K}}\end{array}$} \\
\cline { 1 - 2 } SGCl-1 & 0,74 & \multirow{2}{*}{0,75} \\
\hline SGCl-2 & 0,75 & \\
\hline SGCl-3 & 0,76 & \\
\hline
\end{tabular}

Tab. 3 The evaluation of graphetic shape with help of automatic image analysis

\begin{tabular}{|c|c|c|}
\hline $\begin{array}{l}\text { Sample } \\
\text { designation }\end{array}$ & $\begin{array}{l}\text { Content of } \\
\text { ferrite F, } \\
{[\%]}\end{array}$ & $\begin{array}{l}\text { Average content } \\
\text { of ferrite } \bar{F}\end{array}$ \\
\hline SGCl-1 & 37,8 & \multirow{3}{*}{36,4} \\
\hline SGCl-2 & 39 & \\
\hline SGCl-3 & 32,6 & \\
\hline
\end{tabular}

Tab. 4 The evaluation of ferritic content with help of automatic image analysis

\section{SELECTION OF TYPE OF FINITE ELEMENTS AND SIZE OF ELEMENT}

The designed model of SGCI material structure was concerned with doing of sensitivity analysis tab. 5 relating to change of intensity of stress distribution around the graphetic particles. The graphetic particles are designed as cavities without finite element web. On the base of the sensitivity analysis, the determined size of elements was 0,0005 mm. This mentioned size of elements ensures good uniformity and accuracy of resolution and the error is not higher than 2,5\%. Linear triangular elements Fig. 7 are used for solution. Geometric model was made up for $10 \%$ graphetic proportion in structure, the number of particles was 200 pcs $/ \mathrm{mm}^{2}$ and size was chosen in the interval from $30 \mu \mathrm{m}$ to $60 \mu \mathrm{m}$.

\begin{tabular}{|c|c|c|c|c|}
\hline $\begin{array}{l}\text { Size of } \\
\text { elements }\end{array}$ & $\sigma_{y y}$ & $\sigma_{z z}$ & $\sigma_{y z}$ & $\sigma_{\mathrm{HMH}}$ \\
\hline 0,01 & 1,215 & 0,0516 & 0,012 & 1,042 \\
\hline 0,009 & 1,209 & 0,0461 & 0,0033 & 1,038 \\
\hline 0,008 & 1,208 & 0,0464 & 0,0055 & 1,036 \\
\hline 0,007 & 1,225 & 0,0371 & 0,0185 & 1,059 \\
\hline 0,006 & 1,489 & 0,146 & 0,048 & 1,211 \\
\hline 0,005 & 1,501 & 0,16 & 0,028 & 1,206 \\
\hline 0,004 & 1,780 & 0,246 & 0,0011 & 1,388 \\
\hline 0,003 & 1,947 & 0,271 & 0,0060 & 1,510 \\
\hline 0,002 & 2,385 & 0,384 & 0,013 & 1,819 \\
\hline 0,001 & 2,800 & 0,310 & 0,0069 & 2,247 \\
\hline 0,0009 & 2,780 & 0,285 & 0,164 & 2,270 \\
\hline 0,0008 & 2,904 & 0,266 & 0,048 & 2,369 \\
\hline 0,0007 & 2,861 & 0,237 & 0,0821 & 2,358 \\
\hline 0,0006 & 2,925 & 0,215 & 0,0864 & 2,436 \\
\hline 0,0005 & 2,931 & 0,180 & 0,0089 & 2,467 \\
\hline 0,0004 & 2,918 & 0,146 & 0,013 & 2,479 \\
\hline 0,0003 & 2,916 & 0,107 & 0,007 & 2,507 \\
\hline
\end{tabular}

Tab. 5 The evaluation of content of graphite with help of automatic image analysis

where

$\sigma_{y y}$ - stress in the direction of loading, [MPa]

$\sigma_{z z}$ - stress which is perpendicular to direction of loading, [MPa]

$\sigma_{y z}$ - shear stress, [MPa]

$\sigma_{\mathrm{HMH}}$ - equivalent stress with reference to $\mathrm{HMH}$ theory, [MPa] 

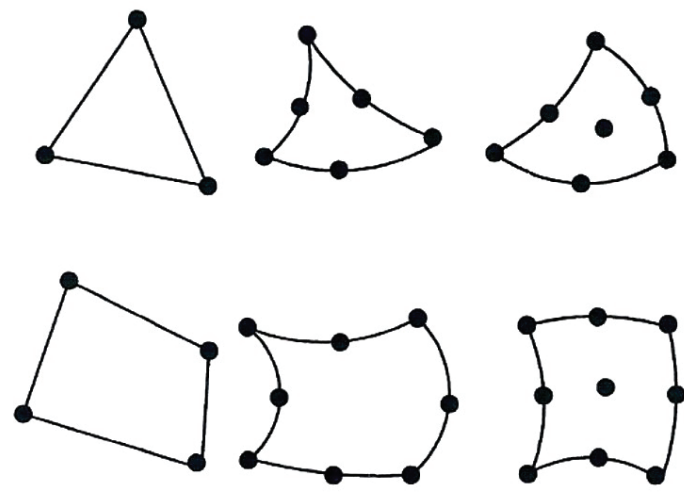

Fig. 7 Types of elements for 2-D space

\section{GEOMETRIC MODEL OF SGCI}

The shape of the graphetic particle has a significant influence on size of eigenfrequences as well as there is the influence on state of surrounding stress. If we want to evaluate the quality of graphetic particle, we have to determine some geometric characterizations which describe the mentioned particle. The given determination is also closely connected with the method of measurement of these characterizations [11]. The precise description of boundary relating to graphetic particles can only be obtained during the process of evaluation of results of FEM analysis. This partial restriction is caused by impossibility to obtain any other description of boundary. It can be done only by help of web of finite elements.

The first phase of preparation of models is concerned with determination of basic model properties. Matrix could be considered to be a homogenous structure with the linear dependency deformation - stress. Graphetic particle could be the cavity which could be designed in a specific way and it means that the web of the finite elements would not be created in the area of this cavity. This type relating to modeling of graphetic particles is possible because of their properties: low tension and frequent decohesion from matrix. Calculation as well as statistic evaluation of results could be done only after generation of large number of geometric models and in this case, the generation should be done for approximately 750 models. During the solving of given task, We decided to create the automatic model generator which operates on the base of generating of random numbers [11].
From the point of view of materials engineering, the preparation of geometric model is closely connected with the utilization of characteristic data of SGCl (for purpose of definition of input data). The mentioned characteristic data were obtained on the base of visual image analysis of the experimental material:

\section{the number of graphetic grains for $1 \mathrm{~mm}^{2}: 100 \div$ 300 units, average diameter of graphetic grain: $0,01 \div 0,08$ $\mathrm{mm}$,}

area proportion of graphite in the structure: $4 \div$ $12 \%$.

The portion of graphetic skeleton depends on crystallization rate (growth is subjected to diffusion of carbon) and amount (proportion and number) of eutectic units especially depends on number of nuclei in molten mass (treating agents). These two mentioned factors have significant influence therefore they are the determinative factors for area proportion of graphite in the structure. On the base of the given mentioned fact hereinbefore, we generated the web from points which were connected together and these points can be also understood as representatives of potential centres of graphetic particles. The auxiliary parameter was used for their generation. This auxiliary factor specifies minimal distance between particular graphetic particles. For determination of the given diameter of graphetic particle, we have to generate the auxiliary web of points with the sufficient density, for example $100 \times 100$ points and then we can specify the number of points which belong to individual centres of graphetic particles. The mentioned process is the principle for determination of area proportion for graphite and it is in relation to the individual graphetic particles with the respect to number and size. According to this fact, it is possible to determine the diameter of the individual graphetic particles. This type of change relating to generation of models is connected with the elimination of many problems including size, distribution and number of graphetic particles. On the other side, the diameter of particle can be understood as function of mutual position of graphetic particles and it means that there is not any possibility of occurrence of such particles which would be disproportional from the aspect of "largeness" or size and it also means that there is the elimination of occurrence of too "small" particles of sphe- 
roidal graphite. According to these properties, the algorithm was supplemented by control of scattering relating to size of graphetic particles. In case that the given scattering runs over the determined values, the selection relating to centres of graphetic particles is not suitable for any other analysis and therefore these unsuitable particles are not utilized for any other analysis. The algorithm which was made in this way fulfils all qualitative as well as quantitative parameters. This given algorithm is also supplemented by ability of shape variation for graphetic particles.

Software solution of algorithm is connected with software Octave (share-ware version of Matlab) which is able to generate input file for software GID where spline curves are used for solutions in the area relating to individual graphetic particles. End points of spline are identical but they are not continuous. The post editing of spline curves can help us to obtain continuous areas which represent graphetic particles. Subtraction of the area for graphetic particles from the whole area of investigated model is used for obtaining of resultant geometric model without graphetic particles whereby the boundaries of the model are continuous. This obtained geometric model is saved in IGES format. FEM in software ADINA is used for consecutive analysis because this software allows downloading of geometric data in IGES format. The results of generated "graphetic particles" in software Octave can be found in the Fig. 8. Arbitrary structure of material can be represented by graphetic particles which are randomly generated for creation of the model of various size and shape.

As it has been said, graphetic particle can be understood as a cavity in the structure of material with its various size and shape. The whole problem is based on the solution of the two-dimensional system. The limiting conditions can be represented by taking of degrees of freedom from the whole circumference relating to model. The linear material model with the respect to Young's modulus, also known as tensile modulus $E=2,1 \times 105[\mathrm{MPa}]$, Poisson's ratio $v=0,3$ and mass density $\rho=7850$ $\left[\mathrm{kg} / \mathrm{m}^{3}\right]$ is used.

The area of the resolving is determined for one or more graphetic particles with the size 0,5 $\times 0,5 \mathrm{~mm}$, while graphetic particles are generated in the area $0,45 \times 0,45 \mathrm{~mm}$. This chosen ratio for area of resolution, where graphetic particles are generated, means elimination of influence including eigenfrequences which can be connected with the closeness of boundary for area of resolution. The generated web of finite elements is shown in the Fig. 9. s.m.

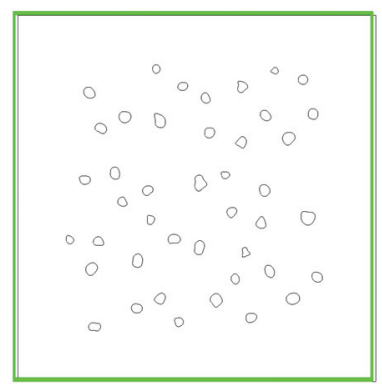

Fig. 8 The process of generation of shapes of graphetic particles in the analyzed areas

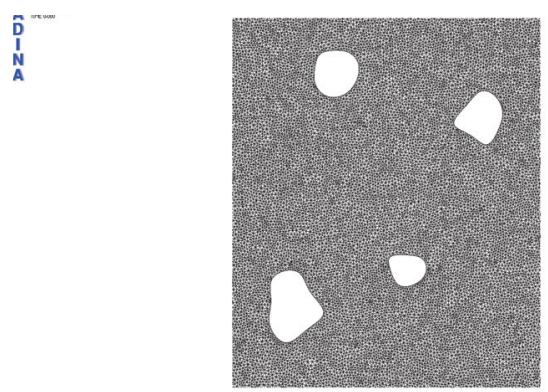

Fig. 9 The generated web of finite elements for more particles

The Fig. 10 and 11 represent only the first and the second shape of eigenfrequency but Fig. 12 and 13 represent the first and the second shape of eigenfrequency with the respect to distribution of stress around the graphetic particles. Fig. 14 and 15 show 750 analyses in dependency on area proportion of graphite for the first and the second shape of eigenfrequency. According to the analysis, we are able to specify that increasing distribution of graphite means decreasing of eigenfrequency.

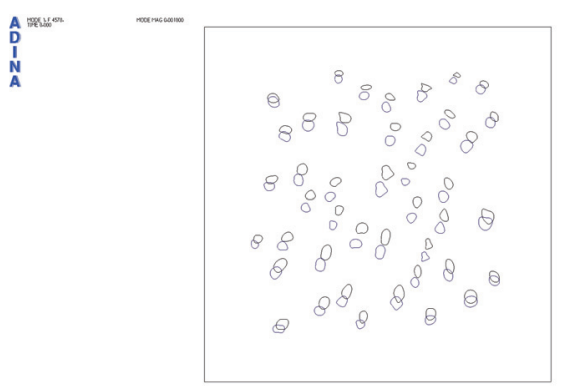

Fig. 10 The first shape of the eigenfrequency 


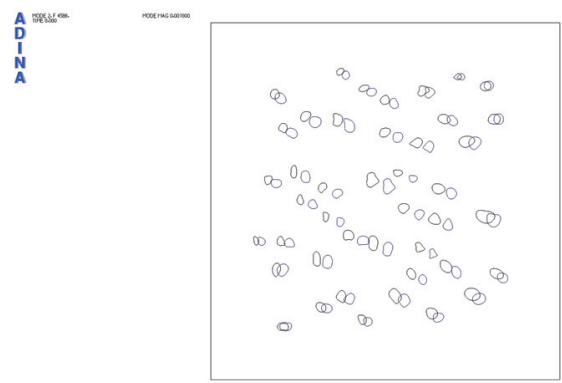

Fig. 11 The second shape of eigenfrequency

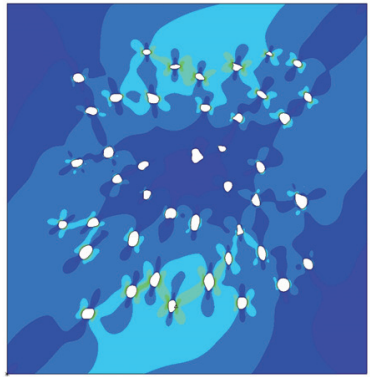

Fig. 12 The first shape of eigenfrequency with the respect to distribution of stress around graphetic particles

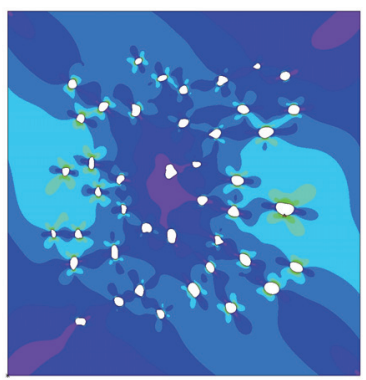

Fig. 13 The second shape of eigenfrequency with the respect to distribution of stress around graphetic particles

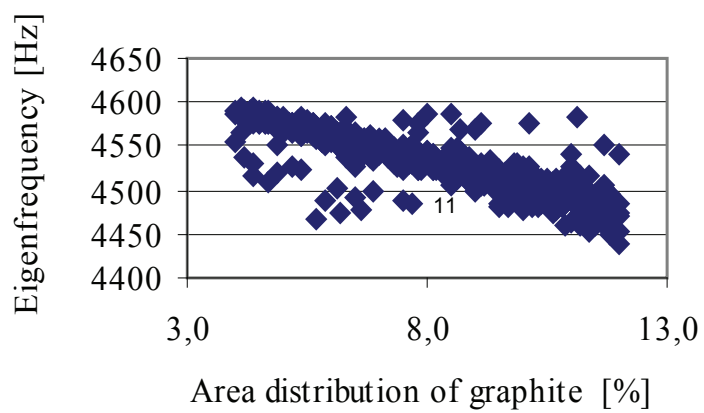

Fig. 14 The first eigenfrequency for different area proportion of graphite

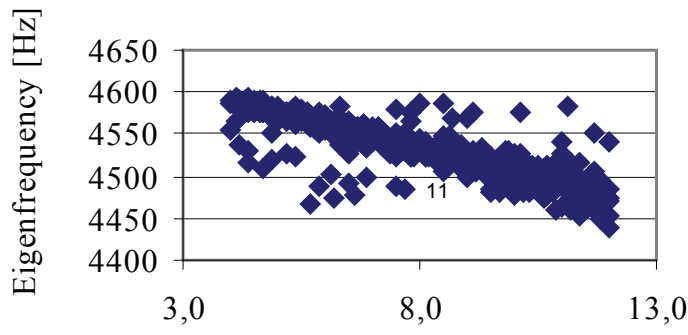

Area distribution of graphite [\%]

Fig. 15 The second eigenfrequency for different area proportion of graphite

\section{CONCLUSION}

The given analysis showed that decreasing of eigenfrequency is subjected to increasing of graphetic distribution. According to this mentioned fact, we can say that ductile cast iron has perfect absorbing or damping capacity.

Existence of graphetic particles in matrix causes concentration of stress and the intensity of the given stress depends on the shape of graphetic particles. The concentration of stress is increased by irregularity of graphetic particle. The most perfect distribution is found out for spheroidal shape relating to sphere. The mentioned process relating to investigation can be used for any other types of cast structures, for example for grey cast iron with lamellar graphite etc. The results which are obtained on the base of analyses represents the first information about loading and properties of the whole system or structure of material and the most important fact is that this given information is known before the given technological processing.

\section{ACKNOWLEDGEMENT}

The work presented in this paper was supported by VEGA grant No. 1/0157/08 and KEGA grant No. 3/7414/09.

\section{REFERENCES}

[1] SHEN G., ROLLINS J., FURRER D., Microstructure Modeling of Forged Waspaloy Discs. Superalloys 1996, KISSINGER, R. D. et al. (Ed.). TMS, 1996, pp. 613-620

[2] DOBRZAŃSKI L. A., ŚLIWA A., TAŃSKI T., Finite Element Method application for modelling of mechanical properties. In Computational Materials Science and Surface Engineering [online]. 2009, vol. 1, pp. 25-28 [cit. 2010-9-3] 
[3] DUARTE C. A., BABUŠKA I., ODEN, J. T., Generalized finite element methods for three-dimensional structural mechanics problems. In Computers \& Structures [online]. 2000, vol. 77, pp. 215-232 [cit. 2010-9-3].

[4] CHAWLA N., GANESH V. V., WUNSCH, B., Threedimensional (3D) microstructure visualization and finite element modeling of the mechanical behavior of SiC particle reinforced aluminum composites. In Scripta Materialia 2004, vol. 51, pp. 161-165 [cit. 2010-9-3].

[5] Palček P., Chalupová M., Fraktografia a mikrofraktografia lomov, Letná škola únavy materiálov 98, Rajecké Teplice, 1998.

[6] Dekazinczy F., Effect of Small Defects on the Fatigue Properties of Medium-Strength Cast Steel, Iron Steel Inst., 208,1970,pp.851-855.

[7] Murakami Y., Metal Fatigue: Effcts of Small Defects and Nonmetalic Inclusions, First edition, Elsevier Science, 2002.

[8] Skočovský P., Bokůvka O., Konečná R., Tillova E., Náuka o materiáli pre odbory strojnícke, EDIS ŽU, Žilina, 1994.

[9] Nelder J. A., Mead R., A Simplex Method for Function Minimization, Computer Journal, 7,1965, pp.308-313.

[10] STN 420461 Hodnotenie metalografickej štruktúry liatín.

[11] Handrik M., Algoritmizácia modelovania stavu napätosti v mikroštruktúra LGG liatin, DP, ŽU v Žiline,2008

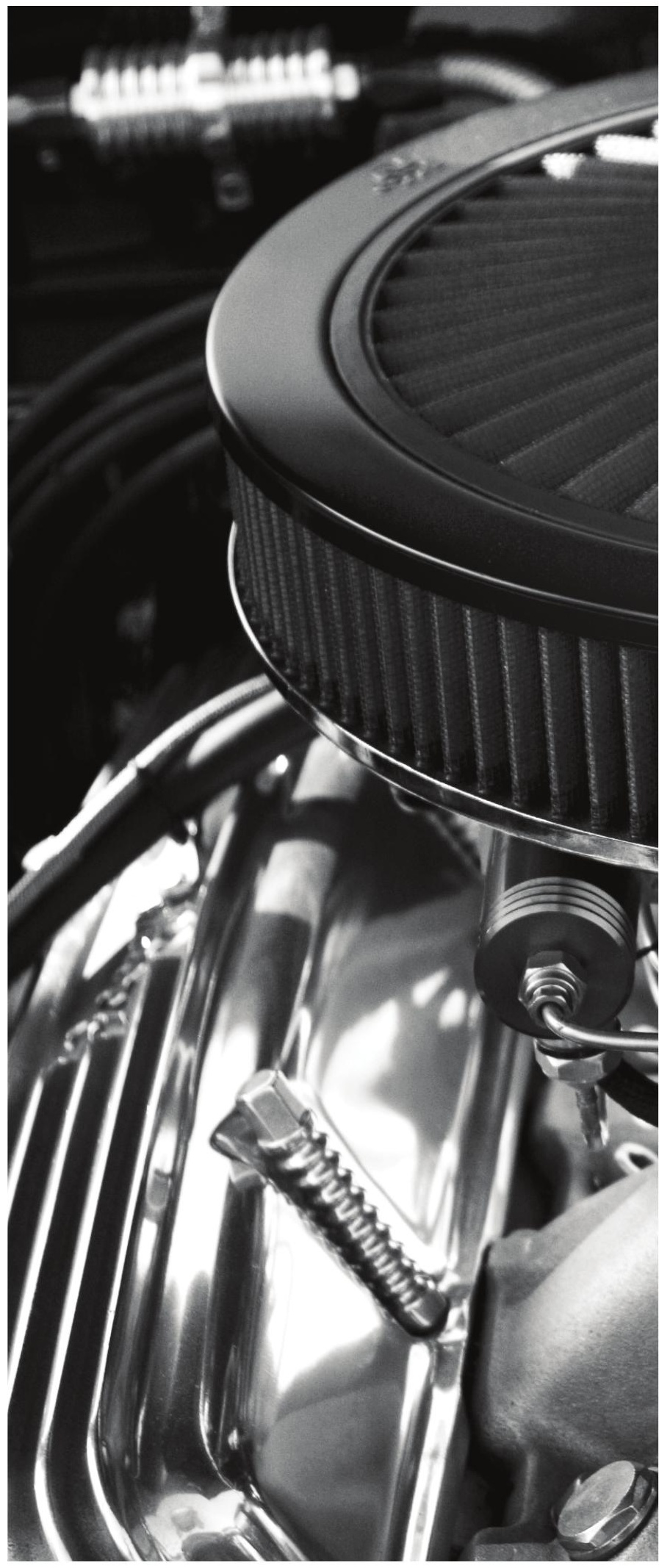




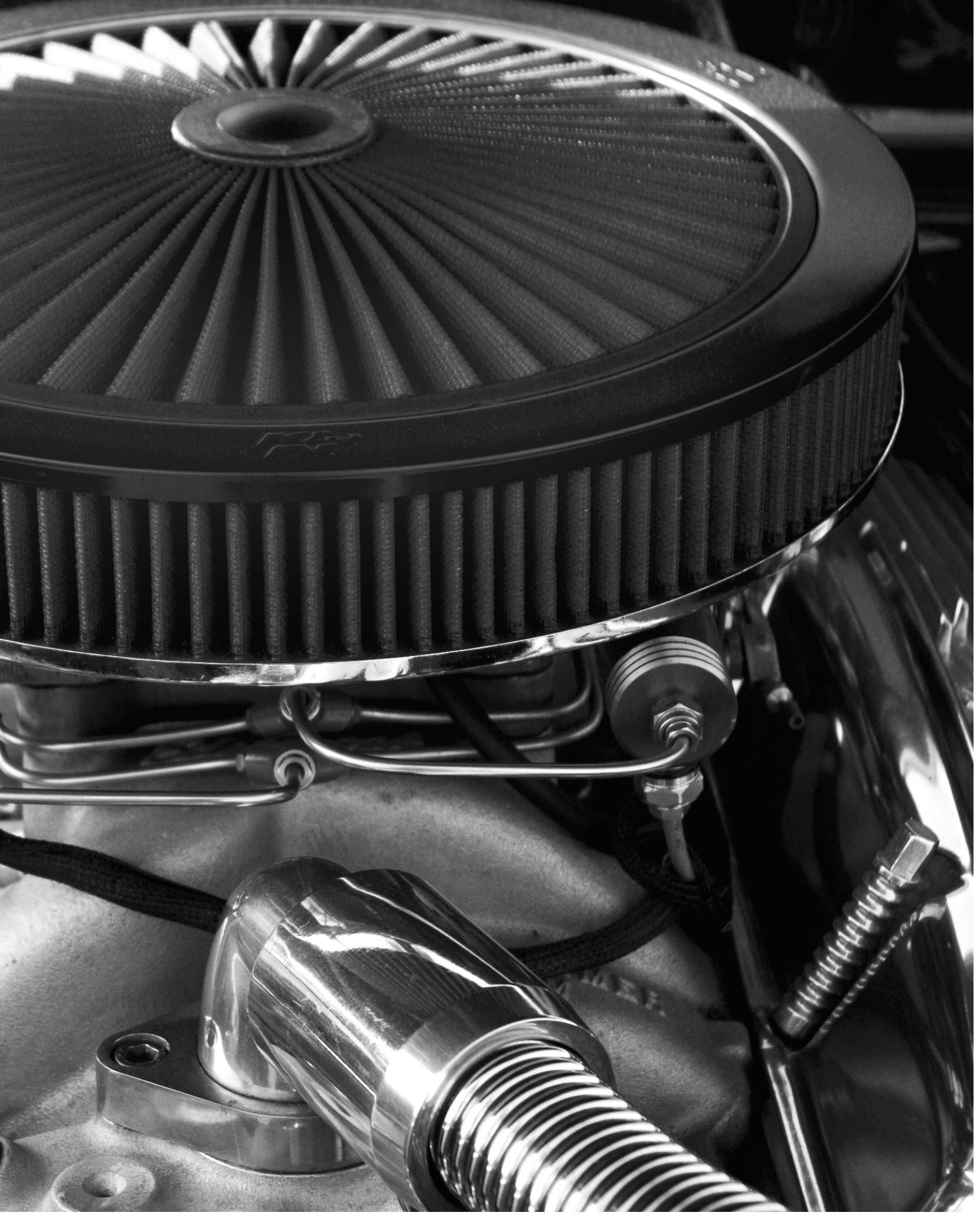

